

\title{
Evaluation of the Functions and Radiographic Severity of Osteonecrosis of the Head of Femur in South-west Nigeria Thanni LO, Gbadegesin SA
}

Department of Orthopaedics and Traumatology, Olabisi Onabanjo University Teaching Hospital, Sagamu, Ogun State, Nigeria

\author{
*Correspondence: Professor LOA Thanni, Department of Orthopaedics and Traumatology \\ Olabisi Onabanjo University Teaching Hospital, PMB 2022, Sagamu 121001, Ogun State, Nigeria. \\ E-mail: loathanni@yahoo.com; ORCID - https://orcid.org/0000-0003-0619-2042.
}

\begin{abstract}
Background: Osteonecrosis of the femoral head is likely to be a complex of diseases rather than a single entity. In subSaharan Africa, epidemiological studies on the subject are uncommon.

Objectives: To determine hip function, radiographic severity and other characteristics of patients with osteonecrosis of the femoral head (ONFH) at presentation in a sub-Saharan Africa population

Methods: A combined prospective clinical survey and retrospective chart review of patients was done.

Results: Fifty hips in 44 patients were studied ( 29 retrospectively and 15 prospectively). The prevalence of ONFH was $1.6 \%$. The mean age was $24.8 \pm 13.2$ years. The lesion was unilateral in $86.4 \%$ and bilateral in $13.6 \%$ of the hips. Sickle Cell Disease (SCD) occurred in $43.2 \%$, sickle cell trait in $13.6 \%$, and $20.5 \%$ of cases were idiopathic. Overall, $12 \%$ of affected hips were presented early, and all the hips were painful at presentation. Of the 18 hips studied prospectively, $72.2 \%$ had necrosis $>30 \%$ and $>30 \%$ subchondral collapse in $61.1 \%$. The mean combined necrotic angle was moderate size, $197 \mathrm{o} \pm 29.7^{\circ}$ and $177.2^{\circ} \pm 69.4^{\circ}$ for the right and left hips, respectively $(\mathrm{p}=0.8)$. The mean WOMAC scores were 37.2 \pm 17.4 for function, $10.2 \pm 4.3$ for pain and $4.2 \pm 2.7$ for stiffness.

Conclusion: Patients with osteonecrosis of the femoral head tended to be young adults and those with SCD. The majority present with large-sized osteonecrosis and subchondral collapse but moderate hip pain and stiffness.
\end{abstract}

Keywords: Avascular necrosis, Femoral head, Hip pain, Sickle Cell Disease, Subchondral collapse, WOMAC score.

\section{Introduction}

Osteonecrosis of the head of the femur (ONHF) or osteonecrosis of the femoral head (ONFH) develops when blood supply to the femur head is interrupted. The resulting ischaemia leads to focal necrosis and later depression or collapse of the head of the femur. The damage to the head of the femur ultimately leads to osteoarthritis of the hip joint. Although avascular osteonecrosis occurs in other sites, such as the head of the humerus and the medial condyle of the femur, the femoral head is the most common site of occurrence.

ONFH is also referred to as aseptic necrosis and avascular necrosis (AVN). It is a common hip condition worldwide, associated with several 
possible causes. Some of the aetiological factors include trauma, haemoglobinopathies such as sickle cell disease (SCD), steroid use, alcohol abuse, smoking, connective tissue diseases such as systemic lupus erythematosus (SLE), diabetes mellitus, hyperlipidaemia, fat embolus syndrome, coagulopathy, impaired fibrinolysis, gout, vasculitis, HIV infection, Gaucher's disease, pancreatitis, cancer chemotherapy and radiation therapy. ${ }^{[1-5]}$ Nevertheless, many cases of ONFH are idiopathic.

In Africa and Brazil, SCD, a genetic disease, is a frequent aetiological factor of osteonecrosis of the head of the femur. [5-7] In Europe and North America, steroid use and alcohol abuse are common causes for $80 \%$ of non-traumatic cases. ${ }^{[8]}$ In a report from Belgium, SCD was associated with only $5.7 \%$ of the cases. [9] In a series from Nigeria, $80 \%$ of patients with haemoglobinopathies who had ONFH had homozygous $\mathrm{HbS}$, while $20 \%$ had HbSC. [10] These authors had previously reported that SCD was the aetiology of ONFH in $44.8 \%$ of all cases, irrespective of haemoglobin genotype. [11]

Non-traumatic osteonecrosis is most common in productive young ages. Most patients are aged 30 to 40 years, ${ }^{[3,12]}$ although patients as young as 20 years old are not uncommon. ${ }^{[10]}$ Although there are no population studies from sub-Saharan Africa, incidence rates of 2 per 100,000 and 2.5 per 100,000 persons have been reported from the UK and Japan, respectively. [13, 14] Males are more frequently affected. [9] This male sex prevalence may be as thrice or more than in females. ${ }^{[12]}$ The reason for male preponderance is unknown, but it may be due to more vigorous physical activities among males. The disease is also commonly bilateral $(62 \%)[1,9]$ thus, worsening an already adverse quality of life. [15] If untreated, more than $65 \%$ of asymptomatic patients and $85 \%$ of symptomatic ones are likely to progress to femoral head collapse. ${ }^{[1]}$ Normal function can be defined as painless and supple hip in a person who performs activities of daily living without any difficulty.

Blood supply to the head of the femur is from anastomosis of three sources. Retinacular arteries are mainly from the medial circumflex femoral artery, and to a lesser extent, the lateral circumflex femoral artery. The terminal branches of the medullary artery of the femur also contribute. Probably the least contribution is from the artery of the ligamentum teres, a branch of the obturator artery. The definite pathogenesis leading to ischaemia is unknown, but there are hypotheses. There is the theory of endothelial dysfunction. This, in addition to hypercoagulability and stasis, are the cause of deep vein thrombosis (DVT). It is thought that thrombi cause occlusion of arteries in the head of the femur. A population-based study in Taiwan showed a significantly higher incidence and risk of venous thromboembolism (VTE) in AVN patients than in the general population. [8] Molecular and genetic factors are also thought to play an essential role in the pathogenesis of AVN.

Dysregulation of angiogenesis and disturbance of osteogenesis by inhibition of osteogenic differentiation of mesenchymal stem cells (MSC) are known to be involved. [16] This is the basis of various surgical techniques in the management of early cases of ONFH. The techniques include injection of concentrated bone marrow aspirate as a source of MSCs, attempts at stimulating revascularization in the affected segment after core decompression by insertion of vascularized fibular graft and tantalum rod. ${ }^{[17]}$ Drug treatment using teriparatide and bisphosphonates is aimed at modulating osteogenesis. Teriparatide is known to induce osteoblast activity and thereby increase bone mass. [18] On the other hand, Bisphosphonates inhibit osteoclast activity, thus preventing the resorption of bone. ${ }^{[19]}$ Alcohol and steroid use has been shown to induce osteocyte apoptosis around the area of osteonecrosis. This apoptosis results in reduced 
sclerostin expression, which is a genetically encoded osteocyte-derived protein. [20] Elevation of serum TNF- $\alpha$ concentration and bone marrow expression has been demonstrated in steroidinduced AVN. Increased concentration of TNF- $\alpha$ in the area of necrosis, produced by macrophages, enhances inflammation and aggravation of osteoclast activity. From the foregoing, it is apparent that $\mathrm{AVN}$ is a complex disease with varying pathogenesis rather than a single disease entity. Therefore, the expression of the disease in affected patients may be influenced by aetiological factors and pathogenesis.

Epidemiological studies of this condition are uncommon, especially in sub-Saharan Africa; hence it is necessary to establish baseline characteristics of patients with this condition. This idea will assist with the development of specific preventive and treatment options. The objectives of this study were to determine hip function, radiographic severity and other characteristics of patients with osteonecrosis of the femoral head at presentation in a Sub-Saharan Africa population.

\section{Methods}

The study was conducted between January 2013 and January 2020 at the Olabisi Onabanjo University Teaching Hospital, Sagamu, Southwest Nigeria. Consecutively presenting patients with ONFH were included in the study. The database of the Medical Records Department for Orthopaedic Clinic patients was examined retrospectively to flag all cases of osteonecrosis of the head of the femur diagnosed by symptoms, signs and radiographic confirmation. The case files of all identified patients were retrieved and scrutinized for relevant information. There was no age restriction as all patients diagnosed with osteonecrosis of the head of the femur were selected.
The data extracted from the records included demographic data, history, affected hip joint, documented evidence of the radiographic confirmation of diagnosis, including Ficat and Arlet staging, haemoglobin genotype and other aetiological risk factors. The demographic data included age, sex, weight $(\mathrm{kg})$, and height $(\mathrm{m})$. Body Mass Index (BMI) was calculated as weight $(\mathrm{kg})$ / height $(\mathrm{m})^{2}$. These data were also documented for the prospective arm of the study.

Prospectively, cases of ONFH seen in the Orthopaedic Clinic were assessed by a Consultant Grade Orthopaedic Surgeon. Demographic data and history of the condition were documented as in the retrospective arm of the study. After clinical examination, each patient completed a Western Ontario and McMaster Universities Index (WOMAC) questionnaire. [21] An orthopaedic registrar assisted patients who were not educated to complete the form. The WOMAC questionnaire is a validated instrument for assessing functions in patients with osteoarthritis of the hip and knee. The questionnaire has three segments, each assessing pain, joint stiffness, and physical function separately. It contains a total of 24 variables. Because of segmentation of the variables, patients can be compared for pain, joint stiffness and physical function separately.

Using a visual analogue scale (VAS), the severity of joint pain was scored at the first clinic attendance. The ten-point scale ranged from 0 to 10 , representing no pain and the worst possible pain, respectively. Each patient indicated a point on the scale that best described the severity of their pain. The score was then measured using a ruler. For patients presenting with pain in both hips, each hip was scored separately, and the greater score was taken.

The hip function was assessed using the Harris Hip Score (HHS). [22] The HHS is a validated questionnaire assessing pain, physical function, 
and the range of hip motion. The assessment was completed at the first consultation. Where both hips were symptomatic, each hip was scored separately. Scores were graded as poor $(<70)$, fair (70 - 79), good (80 - 89) and excellent $(90-100)$. WOMAC scores were similarly graded. Function was graded as poor (52 - 68), fair (35 - 51), good (18 - 34) and excellent $(1-17)$. Pain was graded as poor $(16-20)$, fair $(11-15)$, good $(6-10)$ and excellent $(1-5)$ and stiffness as poor $(7-8)$, fair $(5-6)$, good $(3-4)$ and excellent $(1-2)$.

A standard set of investigations were also ordered at the first consultation (haemoglobin genotype, serum uric acid, fasting blood sugar and lipid profile). Digital plain radiograph of both hips was done in standard anteroposterior and lateral views. This form of imaging confirms the size, and stage of the necrosis, according to Ficat and Arlet. [23] When necrosis is identified, the volume of necrosis is determined according to the necrotic angle of Kerboul. [24, 25] When there is a radiographic collapse of the head of the femur, the extent of joint line depression (in millimetres) and the extent of involvement of the head of the femur in the collapse were determined. The same surgeon did all radiographic assessments and measurements.

The ethics review committee approved the study of the study institution. All prospectively included study participants gave informed consent.

The data were entered into a form designed for the research. An electronic database was generated from the latter using Epi Info version 7. Descriptive analysis was done using frequencies and averages. The incidence and prevalence of osteonecrosis were calculated in relation to the total number of patients (cases) attending the Orthopaedic Clinics. Comparison of group characteristics was done using the ChiSquare test, and statistical significance was set at $\mathrm{p}<0.05$.

\section{Results}

Twenty-nine patients and 32 hips were retrospectively reviewed from January 2013 to January 2019, while 15 patients and 18 hips were prospectively studied from February 2019 to January 2020. In all, 44 patients and 50 hips were studied. Thirty-eight patients had unilateral disease $(86.4 \%)$, while 6 had bilateral hip affectation (13.6\%). During the 6-year study period, 2803 new patients were seen in the clinic. The patients diagnosed with osteonecrosis of the head of the femur were $1.6 \%(44 / 2803)$ of the new cases.

There were 24 male and 20 female patients (male$\mathrm{t}$-female ratio of 1.2:1). Their mean age was $24.8 \pm 13.2$ years (range: $5-67$ years). The mean BMI was $21.6 \pm 4.7 \mathrm{~kg} / \mathrm{m}^{2}$. The most common aetiological factor associated with ONFH in this cohort was haemoglobinopathy, as shown in Table I. Nineteen patients $(19 / 44 ; 43.2 \%)$ had SCD while 6 had sickle cell traits, $\mathrm{HbAS}(6 / 44$, $13.6 \%)$. Trauma was less common (4/44, 9.0\%), and there were nine idiopathic cases $(9 / 44$, $20.5 \%)$. The male-to-female ratio among patients with SCD was 1.7:1. There were 14 patients with HbSS, while 5 had HbSC. The mean age of those with $\mathrm{HbSS}$ was $17.3 \pm 5.9$ years, while the mean age of patients with $\mathrm{HbSC}$ was $24.8 \pm 8.8$ years.

There were 20 right and 30 left affected hips (Right-to-Left ratio was 1:1.5). The left hips were affected one and a half times more than the right. According to radiographic staging, only six hips were presented early $(6 / 50 ; 12.0 \%)$, that is, Ficat and Arlet Stages 1 and 2, while 44 hips (44/50; $88.0 \%$ ) were presented late (Stages 3 and 4 ) as shown in Table II. All the affected hips were painful at presentation, and the mean duration of pain at presentation was 24 months (range of 1 month to 11years). 
Table I: Aetiological factors in 44 patients with osteonecrosis of the femoral head

\begin{tabular}{lll}
\hline Aetiology & Frequency & Percentage \\
\hline Sickle Cell Disease & 19 & 43.2 \\
Sickle Cell Trait & 6 & 13.6 \\
Trauma & 4 & 9.1 \\
Alcohol use & 2 & 4.5 \\
Steroid use & 2 & 4.5 \\
Cardiac disease & 1 & 2.3 \\
CVA & 1 & 2.3 \\
Idiopathic & 9 & 20.5 \\
\hline
\end{tabular}

Table II: Ficat and Arlet radiographic staging of osteonecrosis of 50 hips

\begin{tabular}{lll}
\hline Stage & \multicolumn{1}{c}{ Frequency (\%) } \\
\hline & Right Hip & Left Hip \\
1 & $0(0.0)$ & $1(0.0)$ \\
2 & $2(10.0)$ & $3(10.0)$ \\
3 & $11(55.0)$ & $16(53.3)$ \\
4 & $7(35.0)$ & $10(33.3)$ \\
Total & $20(100.0)$ & $30(100.0)$ \\
\hline
\end{tabular}

Fifteen patients and 18 hips were prospectively evaluated for size of necrosis, depression of necrotic area, the extent of involvement of the femoral head, and hip function. The majority of the prospectively evaluated hips, 13/18 (72.2\%), had $>30 \%$ involvement of the head of the femur with osteonecrosis. Similarly, 11/18 (61.1\%) had
$>30 \%$ of the head of the femur with subchondral collapse (Table III). As shown in Table III, the combined necrotic angle of Kerboul was of moderate size in most hips bilaterally. The mean angle of necrosis was $197 \circ \pm 29.7$ for the right hip and $177.2^{\circ} \pm 69.4^{\circ}$ for the left hips ( $p=0.8$ ).

Table III: Radiographic severity of osteonecrosis in 18 patients

\begin{tabular}{llll}
\hline Measure of Severity & & Frequency & \\
\hline \multirow{3}{*}{ Size of necrosis } & $<15 \%$ & Right Hip & Left Hip \\
& $15 \%-30 \%$ & 0 & 2 \\
& $>30 \%$ & 6 & 3 \\
Subchondral collapse & $<15 \%$ & 0 & 7 \\
& $15 \%-30 \%$ & 2 & 1 \\
& $>30 \%$ & 5 & 4 \\
Joint line depression & $<2 \mathrm{~mm}$ & 0 & 6 \\
& $2 \mathrm{~mm}-4 \mathrm{~mm}$ & 4 & 3 \\
& $>4 \mathrm{~mm}$ & 3 & 5 \\
Combined & & & 3 \\
angle & Mecrotic & $197^{\circ} \pm 29.7^{\circ}$ & $177.2^{\circ} \pm 69.4^{\circ}$ \\
& & $168^{\circ}-225^{\circ}$ & $70^{\circ}-260^{\circ}$ \\
\hline
\end{tabular}

*Comparison of mean values: Student's t-test $=0.183 ; \mathrm{p}=0.8$. 
According to the HHS, function in the affected hips was generally poor $(<70)$. The mean HHS for the left and right hips were $53.6 \pm 16.7$ (range: 30 80 ) and $49 \pm 10.5$ (range: 31 - 56), respectively, as shown in Table IV. The difference in mean HHS was not statistically significant $(p=0.5)$. Using the WOMAC index of severity, impairment was moderate for the three subscales of function, pain and stiffness. The mean scores were $37.2 \pm 17.4$, $10.2 \pm 4.3$ and $4.2 \pm 2.7$, respectively. Therefore, the function rating was fair, while pain and stiffness were good.

The mean serum uric acid level $(3.7 \pm 1.7 \mathrm{mg} / \mathrm{dl})$, mean fasting blood sugar $(79.3 \pm 8.2 \mathrm{mg} / \mathrm{dl})$, mean serum cholesterol $(160.1 \pm 65.4 \mathrm{mg} / \mathrm{dl})$, mean highdensity lipoprotein $(69.4 \pm 69.9 \mathrm{mg} / \mathrm{dl})$ and mean low-density lipoprotein $(110.7 \pm 59.8 \mathrm{mg} / \mathrm{dl})$ were within normal limits.

Table IV: Mean scores of assessments of function in 18 patients with osteonecrosis

\begin{tabular}{|c|c|c|c|}
\hline WOMAC Score & & & \\
\hline \multirow[t]{2}{*}{ Function (68) } & Mean & $37.2 \pm 17.4$ & \\
\hline & Range & $6-63$ & \\
\hline \multirow[t]{2}{*}{ Pain (20) } & Mean & $10.2 \pm 4.3$ & \\
\hline & Range & $2-17$ & \\
\hline \multirow[t]{2}{*}{ Stiffness (8) } & Mean & $4.2 \pm 2.7$ & \\
\hline & Range & $0-8$ & \\
\hline \multirow[t]{3}{*}{ Harris Hip Score } & & Right Hip & Left Hip \\
\hline & Mean* & $49 \pm 10.5$ & $53.6 \pm 16.7$ \\
\hline & Range & $31-56$ & $30-80$ \\
\hline
\end{tabular}

\section{Discussion}

The mean age of patients in this study (24.6 years) is consistent with the earlier report of 26.6 years. [11] The younger age contrasts with a mean age at presentation of 48.4years in Western Europe. [9] The patients in the study generally tended to be young adults, while those who specifically had sickle cell disease tended to be adolescents. Patients with SCD tend to suffer from repeat vaso-occlusive events as part of the SCD, which may be the reason for even earlier presentation in them. The greater severity of SCD has been linked with an increased incidence of ONFH. [26] This presents a particularly challenging situation, requiring early diagnosis and treatment to prevent or delay progression to femoral head collapse. As shown in this study, presentation of ONFH is usually late, with a mean duration of hip pain of 24 months, while $88 \%$ presented with advanced radiographic features. Regular imaging studies of asymptomatic hips in SCD is desirable, but more work is required to identify risk factors in this cohort and reduce the rate of unnecessary imaging.

The sex prevalence in this study shows a slight male preponderance. This is different from the slight female preponderance observed in a previous study of ONFH. [11] A male preponderance is the commonly reported pattern as currently observed. [9,12] The most crucial determinant of this pattern of sex prevalence is SCD, the most important aetiological factor in this cohort of patients. In the subset of patients 
with HbSS, there was a clinically important male preponderance of 1.7:1.

In cohorts where steroid use and alcohol abuse are the major aetiology of ONFH, bilateral hip affectation can be more than $60 \%$. [9] In the present study, bilateral affectation occurred in $13.6 \%$ of cases. The reason for this large difference, compared with previous reports, is unclear since both hips are assumed to be equally exposed to the aetiological factor in both situations. This may support the suggestion that avascular necrosis is not one disease entity but a spectrum of diseases with varying pathogenesis. The pathogenesis in sickle cell disease requires elucidation for a better understanding.

An important aspect of this study is the assessment of hip function. The utility of Harris Hip Score (HHS) is in comparing preoperative and postoperative scores, thereby objectively quantifying hip function improvement. Postoperative assessment was not an objective of this study, so only the initial scores were available. The mean score for both hips was poor. The WOMAC score is more discriminating of the subsets of pain, stiffness and function. All subset scores were a grade better than the HHS. While function was fair, pain and stiffness scores were borderline good. The mean WOMAC scores for pain and stiffness were good, similar to scores of 6.6 and 3.1 respectively reported by Hauzeur et al. from Europe. ${ }^{[9]}$

On a three-point scale of small, medium and large, the size of necrosis of the femoral head in the patients in this study was averagely moderate in size. Using Kerboul's classification of the combined angle of necrosis, $161^{0}-1990$ is a moderate size, and the mean for the patients in this study are $197^{\circ}$ for the right and $177^{\circ}$ for the left hips. This is a clinically important observation because such size of necrosis may be directly related to the advanced radiographic presentation noted in most patients. Although this study did not correlate the size of necrosis with the collapse of the femoral head, it has been shown that size $(>30 \%)$, morphology (transverse) and location (lateral and anterior) of osteonecrosis is an important determinant of collapse in ONFH. [27-29] Extension of necrosis laterally to the acetabular edge, ${ }^{[27]}$ and anterior necrotic angle $\geq 79^{\circ}$ are associated with the collapse in steroid-induced ONFH. [28] A limitation of our study is the small sample size; therefore, more extensive studies are required to validate the current findings.

\section{Conclusion}

This study has shown that these patients presented with advanced radiographic stages of ONFH. On average, the volume of the affected head of the femur was moderate in size, often with the collapse of the involved segment. Hip was function was only fair in the majority of the patients, while pain and stiffness scores were good. The most common aetiological factor was sickle cell disease, especially HbSS. Therefore, patients with sickle cell disease should have a frequent radiological examination of their hips to identify ONFH early in the asymptomatic stage. This will engender early treatment to prevent the collapse of the femoral head and thereby improve quality of life.

Authors' Contributions: TLO conceived and designed the study. GSA participated in the study's design, and TLO did data analysis and interpretation. Both authors drafted the manuscript, revised it for sound intellectual content and approved the final version.

Conflict of Interest: None.

Funding: Self-funded.

Publication History: Submitted 15 September 2021; Accepted 14 November 2021.

\section{References}


1. Larson E, Jones LC, Goodman SB, Koo K, Cui Q. Early-stage osteonecrosis of the femoral head: where are we and where are we going in year 2018? Int Orthop 2018; 42: 1723-1728. https://doi.org/10.1007/s00264-018-3917-8

2. Hernigou P, Daltro G, Hernigou J. Hip osteonecrosis: stem cells for life or behead and arthroplasty? Int Orthop 2018; 42: 1425-1428. https://doi.org/10.1007/s00264-018-4026-4

3. Kubo T, Ueshima K, Salto M, Ishida M, Aral Y, Fujiwara $H$. Clinical and basic research on steroid-induced osteonecrosis of the femoral head in Japan. J Orthop Sci 2016; 21: 407-413. https://doi.org/10.1016/j.jos.2016.03.008

4. Adelowo OO, Oguntona S. Avascular necrosis of femoral head associated with connective tissue disease in Nigerians: case series. West Afr J Med 2009; 28: 262-265.

5. Akinyoola AL, Adediran IA, Asaleye CM, Bolarinwa AR. Risk factors for osteonecrosis of the femoral head in patients with sickle cell disease. Int Orthop 2009; 33: 923-926. https://doi.org/10.1007/s00264-008-0584-1

6. Iwegbu CG, Fleming AF. Avascular necrosis of the femoral head in sickle-cell disease. A series from the Guinea Savannah of Nigeria. J Bone Joint Surg Br 1985; 67: 29-32. https://doi.org/10.1302/0301$\underline{620 X .67 \mathrm{~B} 1.3968138}$

7. Daltro G, Franco BA, Faleiro TB, Rosario DAV, Daltro PB, Fortuna V. Osteonecrosis in sickle cell disease patients from Bahia, Brazil: a crosssectional study. Int Orthop 2018; 42: 1527-1534. https://doi.org/10.1007/s00264-018-3905-z

8. Sung P, Chiang H, Yang Y, Chiang J, Chen C, Yip $H$. Nationwide study on the risk of unprovoked venous thromboembolism in non-traumatic osteonecrosis of the femoral head. Int Orthop 2018; $\quad 42$ : 1469-1478. https://doi.org/10.1007/s00264-018-3866-2

9. Hauzeur J, Malaise M, de Maertelaer V. A prospective cohort study of the clinical presentation of non-traumatic osteonecrosis of the femoral head: spine and knee symptoms as clinical presentation of hip osteonecrosis. Int
Orthop 2016; 40: 1347-1351. https://doi.org/10.1007/s00264-015-3079-x

10. Akinyoola $\mathrm{AL}$, Adediran IA, Asaleye CM. Avascular necrosis of the femoral head in sickle cell disease in Nigeria: a retrospective study. Niger Postgrad Med J 2007; 14: 217-220.

11. Thanni LO, Gbadegesin SA, Adebanjo AA, Osundina BA, Olushiyan BF. Osteonecrosis of the head of femur in a Nigerian teaching hospital. Res J Health Sci. 2020; 8: 18-24. http://dx.doi.org/10.4314/rejhsv8i1.3

12. Vardhan H, Tripathy SK, Sen RK, Aggarwal S, Goyal T. Epidemiological profile of femoral head osteonecrosis in the North Indian population. Indian J Orthop 2018; 52: 140-146. https://doi.org/10.4103/ortho.IJOrtho_292_16

13. Lamb JN, Holton C, O'Connor P, Giannoudis PV. Avascular necrosis of the hip. BMJ 2019; 30; 365: 12178. https:// doi.org/10.1136/bmj.12178

14. Yamaguchi R, Yamamoto T, Motomura G, Ikemura S, Iwamoto $\mathrm{Y}$. Incidence of nontraumatic osteonecrosis of the femoral head in the Japanese population. Arthritis Rheum 2011; 63: 3169-3173. https:// doi.org/10.1002/art.30484

15. Osawa $Y$, Seki $\mathrm{T}$, Takigami $\mathrm{Y}$, Kasai T, Ishiguro N. Do femoral head collapse and the contralateral condition affect the patientreported quality of life and referral pain in patients with osteonecrosis of the femoral head. Int Orthop 2018; 42: 1463-1468. https://doi.org/10.1007/s00264-018-3867-1

16. Kao G, Tu Y, Sung P, Wang F, Lu Y, Wu C, et al. MicroRNA-mediated interacting circuits predict hypoxia and inhibited osteogenesis of stem cells, and dysregulated angiogenesis are involved in osteonecrosis of the femoral head. Int Orthop 2018; $\quad 42$ : 1605-1614. https://doi.org/10.1007/s00264-018-3895-x

17. Hu R, Lei $\mathrm{P}, \mathrm{Li} \mathrm{B}$, Liu H, Yang $\mathrm{X}$, Wen $\mathrm{T}$, et al. Real-time computerized tomography assisted porous tantalum implant in ARCO stage I-II non-traumatic osteonecrosis of the femoral head: minimum five-year follow up. Int Orthop 
$\begin{array}{lcr}\text { 2018; } & 42: & 1535-1544 . \\ \text { https://doi.org/10.1007/s00264-018-3899-6 }\end{array}$

18. Arai $\mathrm{R}$, Takahashi $\mathrm{D}$, Inoue $\mathrm{M}$, Irie $\mathrm{T}$, Asano $\mathrm{T}$, Konno $\mathrm{T}$, et al. Efficacy of teriparatide in the treatment of nontraumatic osteonecrosis of the femoral head: a retrospective comparative study with alendronate. BMC Musculoskelet Disord 2017; 18: 24. https://doi.org/10.1186/s12891016-1379-y

19. Yuan HF, Guo CA, Yan CQ. The use of bisphosphonate in the treatment of osteonecrosis of the femoral head: a metaanalysis of randomized control trials. Osteoporosis Int 2016; 27: 295-299. https://doi.org/10.1007/s00198-015-3317-5

20. Chen X, Yang F, Chen Z, He M, Hong G, Huang $\mathrm{J}$, et al. Association of reduced sclerostin expression with collapse process in patients with osteonecrosis of the femoral head. Int Orthop 2018; 42: 1675-1682. https://doi.org/10.1007/s00264-018-3979-7

21. McConnell S, Kolopack P, Davis AM. The Western Ontario and McMaster universities index (WOMAC): a review of its utility and measurement properties Arthritis Rheum 2001; 45: 453-461. https://doi.org/10.1002/15290131(200110)45:5<453::aid-art365>3.0.co;2-w

22. Harsnaes PN, Gromov K, Otte KS, Gebuhr PH, Troelsen A. Harris hip score and SF36 following metal on metal total hip arthroplasty and hip resurfacing - a randomized controlled trial with 5-years follow-up including 75 patients. BMC Musculoskelet Disord 2021; 22: 781. https://doi.org/10.1186/s12891-021-04671-1

23. Ficat RP. Idiopathic bone necrosis of the femoral head. Early diagnosis and treatment. J Bone Joint $\begin{array}{llll}\text { Surg } & \mathrm{Br} & 1985 ; & 67\end{array}$ https:// doi.org/10.1302/0301$\underline{620 X .67 B 1.3155745}$

24. Steinberg ME, Oh SC, Khoury V, Udupa JK, Steinberg DR. Lesion size measurement in femoral head necrosis. Int Orthop 2018; 42: 15851591. $\quad$ https://doi.org/10.1007/s00264-018$\underline{3912-0}$

25. Kerboul M, Thomine J, Postel M, Merle D'Aubigne R. The conservative surgical treatment of idiopathic aseptic necrosis of the femoral head. J Bone Joint Surg (Br) 1974; 56: 291-296.

26. Adesina O, Brunson A, Keegan THM, Wun T. Osteonecrosis of the femoral head in sickle cell disease: prevalence, comorbidities and surgical outcomes in California. Blood Adv 2017; 1: 12871295.

https://doi.org/10.1182/bloodadvances.20170 $\underline{05256}$

27. Kubo Y, Motomura G, Ikemura S, Sonoda K, Hatanaka H, Utsunomiya T, Baba S, Nakashima $Y$. The effect of anterior boundary of necrotic lesion on the occurrence of collapse in osteonecrosis of the femoral head. Int Orthop 2018; $\quad 42$ : 1449-1455. https:// doi.org/10.1007/s00264-018-3836-8

28. Ohzono K, Saito M, Takaoka K, Ono K, Saito S, Nishina T, et al. Natural history of non-traumatic avascular necrosis of the femoral head. J Bone Joint Surg Br 1991; 67: 3-9. https://doi.org/10.1302/0301$\underline{\text { 620X.73B1.1991778 }}$

29. Wu W, He W, Wei Q, Chen Z, Gao D, Chen P, et al. Prognostic analysis of different morphology of the necrotic-viable interface in osteonecrosis of the femoral head. Int Orthop 2018; 42: 133139. https://doi.org/10.1007/s00264-017-3679$\underline{8}$ unrestricted, non-commercial use, reproduction and distribution in any medium provided the original source is adequately cited and credited. 